\title{
MEMORANDUM OP DIE BESWAARSKRIF OOR DIE DIAKENAMP
}

\section{Probleemstelling}

Die probleem in die beswaarskrif voor die Sinode 1973 spits hom toe op die vraag: wat is die objek van die diakonale diens? Is dit die hele gemeente of alleen ' $n$ gedeelte van die gemeente nl. die armes? In verband hiermee moet ook gevra word: welke spesifieke opdrag is inherent aan die diakenamp? Is dit alleen armversorging of moet die tak van die diaken as meer omvattend gesien word?

Die beswaarskrif gaan teen 'n ,limitatiewe bepaling van die diakonale diens". ${ }^{1}$ Daar word dan ook beswaar gemaak "teen die uitsonderingsposisie wat aan die stoflik-behoeftige gelowiges as „armes" (met 'n gepaardgaande etikettering) gegee word"."

\section{Verskillende visies op die diakenamp}

Verskillende pogings is in hierdie eeu onderneem om die diakenamp te omskryf. Daar kan vier visies genoem word:

1. Aan die begin van die $20 \mathrm{e}$ eeu is die diakonat beskou as christelike armversorging. ${ }^{3}$ Waarskynlik is dit gedoen in navolging van Voetius wat die diakonaat opgevat het as "ministerium seu administratio pauperum".' Hierdie siening vind ons o.a. by H. Bouman wat vanuit Hand. 6 konkludeer dat die amp van diakens ingestel is ten behoewe van "de verzorging van de armen der gemeente"." Hierdie siening tref ons ook aan by P. Biesterveld, J. van Lonkhuyzen en R. J. W. Rudolph in artikels wat hulle oor die diakonaat gepubliseer het."

Ook by $A$. Kuyper vind ons die beperking van die diakonaat tot die armes hoewel daar by hom tog ook die besef is dat die diakonaat meer is dan alleen hulp aan die armes. Kuyper gee vir die indeling van die diakonale vakke die volgende motivering: „Ze heeft armoede en lijden te voorkomen, ze heeft armoede te lenigen en lijden te verzachten en eindelijk heeft zich de middelen te verschaffen om aan haar roeping te kunnen beantwoorden". Kuyper laat dan hierop die volgende woorde nog volg: „De opvatting van de Diaconale taak, als bestond die uitsluitend in de bedeling der noodlijdenden, vindt geen verdedigers meer".?

In de Geref. Kerken in Nederland ontstaan daar in die jare twintig 'n boeiende diskussie oor die vraag ,alleen" of „meer" met betrekking tot die diakenamp. ${ }^{\mathrm{B}}$

2. Resultaat van hierdie diskussie was dat daar 'n nuwe omskrywing van die diakonaat kom. Die diakonaat word nou omskryf as „dienst der barmhartigheid aan alle behoeftigen", en dan word onder „behoeftigen” gereken ,armen, zieken, invaliden, krankzinnigen, zenuwlijders, alcoholisten, sociaal-onaangepasten enz." Vertolkers van hierdie siening is K. Dijk," S. U. Zuidema" en F. H. van Meyenfeldt."

3. Die ontwikkeling van en die besinning op die struktuur van 
die diakenamp gaan voort en so sien ons dat daar by $K$. Dijk ook nog ' $n$ ander definiëring van die diakonaat genoem word wanneer hy skrywe: „de barmhartigheidsdienst heeft niet voor ieder dagelijks brood te zorgen, ook niet in elk gezin hulp te bieden, allerminst het sociale werk in z'n brede omvang aan te pakken, maar alleen daar waar nood en gebrek is, en geen enkele regeling of wetgeving voldoende hulp biedt, reddend op te treden". ${ }^{2}$ Definisie van die diakonaat word dan: „Helpen, waar geen helper is”. Hierdie omskrywing vind ons by 0 . C. Broek Roelofs, ${ }^{13} \mathrm{~J}$. van Klinken ${ }^{14}$ en N. H. Ridderbos, wat die formulering nog enigsins uitbrei met die woorde dat die diaken is ,de pleitbezorger... van allen die geen helper hebben en bewust of onbewust hongeren en dorsten naar de gerechtigheid van het Koninkrijk van God". ${ }^{15}$

4. 'n Vierde omskrywing vind ons ten slotte by $F . H$. van Meyenfeldt wat op grond van Hand. 6 die diakenamp beskou as 'n diens in die koninkryk van God om die gemeenskap van die heiliges te komponeer en te integreer. ${ }^{10}$ Ook 0 . C. Broek Roelofs dink in hierdie rigting, hoewel sy opvatting omtrent die diakonaat nie 'n eenheid vorm nie. ${ }^{17} \mathrm{H}$. N. Ridderbos sien ook die diakenamp gerig op die gemeenskap van die heiliges. In verband hiermee skrywe hy: „... broeders diakenen, ... U hebt niet alleen met de arme mensen te doen, als die er nog zijn, maar u hebt ook met de gemeente te doen: zij is ook uw object... revalidatie van het lichaam van Christus als dienende gemeenschap, dat is de grote en grootse taak van de diaken. ${ }^{18}$

\section{Ekskurs oor Hand. 6}

Hand. 6 word deur baie geleerdes beskou as die locus classicus vir die instelling van die amp van diaken. H. Bouman vertolk die gedagtes van verskillende eksegete wanneer hy skrywe: „Wij mogen dan ook als vaststaand aannemen, dat in Hand. 6 de dienst der barmhartigheid is ingesteld, en dat van de Jeruzalemsche gemeente deze dienst der barmhartigheid naar de andere gemeente is overgeplant". ${ }^{19}$ Nie alleen wat die instelling van die diakenamp betref word verwys na Hand. 6 nie, maar ook wat betref sy struktuur en sy eie funksie.

Aan die een kant word uit hierdie hoofstuk afgelei dat die diaken tot taak het om die armes te versorg ${ }^{20}$ of moet voorsien in tydelike node 21 en aan die ander kant is daar eksegete wat uit hierdie hoofstuk die diaken as die komponis van die gemeenskap sien oprys. ${ }^{22}$

$\mathrm{K}$. Dijk is egter die tolk van baie ander eksegete wanneer hy stel dat ons nie te veel uit Hand. 6 met betrekking tot die diaken moet aflei nie. Dijk vat dan die bedenkinge soos volg saam: 1. Stefanus en Filippus doen evangelistewerk; 2 . Hand. 6 praat nie van armversorging nie; 3 . In die boek Handelinge word nie van diakens gepraat nie; 4. Op die vergadering te Jerusalem (Hand. 15) is nie diakens aanwesig nie; 5 . Die sewe manne wat in Hand. 6 gekies is word nie diakens genoem nie, terwyl die term diaken 'n baie algemeen naam is. 
Tog is Dijk in sy eindkonklusie weer terughoudend en sê hy „dat in Hand. 6 wel van een aparte amptelijke dienst der barmhartigheid sprake is, maar deze dienst, dit blijkt uit alles, droeg niet de naam van diakenschap, en is althans in Jerusalem van tijdelijke aard geweest". ${ }^{23}$ Dieselfde versigtigheid ten opsigte van die ontstaan van die diakenamp vind ons ook by J. Hovius. ${ }^{24}$

Dijk moet dus erken dat daar in Hand. 6 wel 'n diakonale aspek aanwysbaar is. Wanneer ons Hand. $6: 1-7$ nader gaan bekyk dan is dit tog wel seker dat daar eksegeties genoegsame gronde is om te aanvaar dat ons in hierdie hoofstuk te doen het met die instelling van ' $n$ amp watter amp dit ook al mag wees. In die eerste plek kry ons 'n gedetailleerde beskrywing van die ordelike en formele aanwysing van die sewe manne en in die tweede plek is daar 'n duidelike ooreenstemming met die bevestiging in die amp van apostel (Hand. $1: 15-26$ ) en ouderlinge (Hand. $14: 23$ ).

Dit bly vreemd dat ons nêrens lees dat hierdie manne besig was om as diakens in die gemeenskap op te tree nie. G. Stählin beskou die manne met hul Griekse name as die „Führungsgruppe des hellenistischen Gemeindeteils". ${ }^{25}$

Daar is nogal sterk argumente dat ons in Hand. 6 die instelling van die ouderlingamp kry, want dit bly 'n vreemde verskynsel dat Lukas in Hand. $11: 27-30$ die ouderlinge by sy lesers introduseer sonder om op een of ander manier melding te maak van hul aanstelling. Dit skep die indruk dat die bestaan van ouderlinge deur Lukas by sy lesers as bekend veronderstel word.

Ons moet miskien selfs aanvaar dat ons in Hand. 6 nog met ' $n$ ongedifferensieerde amp te doen het. 'n Nuwe amn vloei uit die apostelamp uit. Hierdie amp is egter nog geweldig omvattend, want die sewe manne word geroep tot opsig oor: 1. Die versorging van die weduwees; 2 . die stoflike gemeenskap van die gelowiges; 3 . die eenheid en gemeenskapslewe van die gemeente; 4 . waarskynlik selfs die viering van die heilige nagmaal; 5 . selfs skyn die bediening van die doop nie uitgesluit te wees uit hul werk nie; 6 . die verkondiging van die Woord.

Hoe dit ook al mag wees en wat ook al aan hierdie sewe manne toevertrou is (eksegete verskil hieroor onderling) seker is dat hulle amp elemente bevat van al drie die ampte soos ons hulle vandag ken.

Die sewe manne wat in Hand. 6 gekies word was in ieder geval ó́k ouderlinge. Die gedagte dat ons in Hand. 6 met die instelling van die ouderlingsamp te doen het, word nog bevestig deur die feit dat hierdie manne die titel gedra het van Die Sewe (Hand. $21: 8$ ). Dit roep herinneringe op aan die oudstes van die Joodse sinagoge. Algemeen word aanvaar dat die Palestynse gemeente, dus met name die gemeente te Jerusalem die instituut van oudstes of ouderlinge oorgeneem het van die Joodse sinagogale gemeenskap. ${ }^{23}$

Hierdie sewe manne was dus ouderlinge, hoewel nie alleen ouderlinge nie. Hulle prediking met name dié van Stefanus en Filippus wys op die amp van dienare van die Woord en versorging van die weduwees dui op 'n diakonale aspek van hul amp. Wanneer ons egter na die uitdruklike formulering van Hand. 6 luister dan is daar tog weer probleme. Hand. 6 : 1 spreek baie duidelik van die daaglikse 
versorging van die weduwees, terwyl in Hand. $6: 2$ oor die bediening van die tafels gespreek word. Die bediening van die tafels het meer ingehou dan alleen maar die versorging van die (Griekssprekende) weduwees.

E. Haenchen sien die bediening van die tafels nie as die ,general financial administration of the community" nie maar as "Armenfürsorge". ${ }^{27}$ Wanneer dit so is dan is die arbeid van die sewe manne wat gekies word duidelik gerig op leniging van stoflike nood. F. W. Grosheide sê nadruklik na aanleiding van Hand. $6: 2$; „In ieder geval hebben we te maken met een soort armenzorg".."

Wanneer ons egter die uitdrukking „,die bediening van die tafels" nader gaan ondersoek, dan is dit wel 'n vraag of daarmee een van die aspekte van die diakonale taak aangedui word. Grosheide wys daarop dat by die woord tafels 'n lidwoord ontbreek wat 'n onbepaalde indruk van die tafels gee. ${ }^{29} \mathrm{Hy}$ stel daarom voor om die uitdrukking: die bediening van die tafels figuurlik te verstaan. ${ }^{30}$ L. Goppelt verklaar die formule ,die bediening van die tafels" in die lig van Hand. 2 : 42, 46. Daarom sê hy dat die uitdrukking ,om die tafels te bedien" ' $n$ omskrywing is van ,die gemeinsamen sakralen Mahlzeiten der Urgemeinde von Jerusalem... (Ag. 2, 42, 46), die durch die sogenannte Gütergemeinschaft eine in der übrigen Urchristenheit unbekannte Prägung erheilten". ${ }^{31}$

H. W. Beyer erken dat die sg. "Tischdienst" 'n omstrede saak is. Is dit alleen gerig op die noodlydendes of op die hele gemeente? Beyer is van oordeel dat die laaste opvatting die mees waarskynlike is. „Dann erklärt sich das Ubersehen der hellenistischen Witwen nicht als eine slechte Behandlung zugunsten von anderen, also nicht ein kleinlichter Streit um bessere oder slechtere Fleischstücke, sondern als Meinungsverschiedenheit darüber, ob die hellenistischen Frauen überhaupt zu dieser Tischgemeinschaft und damit zur Gemeinde gehören oder nicht". ${ }^{32}$

Die bediening van die tafels was volgens hierdie opvatting nie net vir die armes bedoel nie, maar vir die hele gemeente. Hierby kom nog die argument dat dit gelyk het of gedurende die eerste eeue van die Christelike kerk die liefdesmaal nie 'n afsonderlike maaltyd was nie, maar 'n bestanddeel van die nagmaalviering."

Al hierdie opvattinge moet ons wel uitermate versigtig laat wees om uit Hand. 6 nie te veel konklusies te trek met betrekking tot die amp van diaken nie.

\section{Die besondere amp van diaken}

Die N.T. leer ons 'n diakonia in ruimere sin wat kan geld as die grondwet van die koninkryk van God, nl. diakenamp van die gelowiges. Die dienaars van 'n koning word diakonoi genoem (Matt. $22: 13$ ): Die owerheid is Gods diakonos (Rom. $13: 4$ ). Christus word ook Diakonos genoem (Gal. 2 : 17; Rom. $15: 8$ ). Paulus dui homself aan as 'n diaken (1 Kor. $3: 5$ ).

Maar ook ken die N.T. in die gemeente van Christus persone wat tot 'n spesifieke taak geroep is. Hulle word ook aangedui met die woord diakonoi. Daar is twee plekke in die N.T. waar die term 
diakonos 'n spesifieke betekenis het nl. Fil. $1: 1$ en 1 Tim. $3: 8,12$. Hier beteken diakonos, ,die feste Bezeichnung des Trägers eines bestimmten Gemeindeamtes in der sich bildenden Kirchlichen Verfassung". ${ }^{34}$ Uit Fil. 1: 1 kan ons die konklusie trek dat daar in die beginperiode van die kerk van die N.T. reeds twee ampte in die gemeente was en hierdie ampte was nou aan mekaar verbonde.

In 1 Tim. 3 word die vereistes vir ouderlinge genoem (vs. 1-7) en die vereistes vir diakens (vs. 8-15). Dit is opvallend dat die vereistes vir die twee ampte nie baie van mekaar verskil nie. Wel moet dit ons tref dat in 1 Tim. $3: 8$ e.v. die vereiste om te leer (soos in vs. 2 dit vir die ouderlinge gestel word) nie genoem word nie. H. W. Beyer beklemtoon dat in die sg. diakenspieël die nadruk val op eienskappe wat nodig is vir manne wat baie in allerlei huise kom en wat met aardse goedere vertroud is." ${ }^{35}$

Ons kan egter meer oor die taak van die diakens te wete kom wanneer ons let op die gawes wat nodig is om as diaken in die gemeente te kan dien. Daar is in die N.T. ' $n$ innige samehang tussen gawe en amp. Wanneer ons vra: watter gawe skenk Christus as onderbou vir die besondere amp van diaken, dan vind ons die antwoord in Rom. $12: 8$ : die gawe om uit te deel en om barmhartigheid te bewys. Die vraag is of dit om twee gawes gaan soos Calvyn gedink het" ${ }^{3 \prime}$ of net om een gawe soos H. N. Ridderbos dit stel.37 In ieder geval is duidelik dat hierdie gawe wys op barmhartigheidsdiens of onderlinge hulpbetoon. In 1 Kor. $12: 28$ word die gawe wat vir diakens vereis word in hul diens aangedui as "onderlinge diensbetoningen" of „bekwaamheid om te dien". ${ }^{3 *}$ Die werk van 'n diaken bestaan dus in diensverlening, barmhartigheidsdiens aan hulle wat dit nodig het.

Wanneer ons aanvaar dat ons in Hand. 6 in sekere sin staan by die wieg van die diakenamp (en ook van die ouderlingamp) dan kan ons uit hierdie hoofstuk wel 'n antwoord kry op die vraag na die diepste kern van die diakenamp. Hoewel dit baie moeilik is om uit Hand. 6 bepaalde konklusies te trek ten opsigte van die instelling van die diakenamp omdat ons hier met 'n nog ongedifferensieerde amp te doen het, is dit wel duidelik dat in hierdie bekende en omstrede hoofstuk ' $n$ amp ingestel is met duidelik diakonale aspekte.

Die amp in Hand. 6, 'n nog ongedifferensieerde amp, is uit die nood gebore. Wat was die nood, die behoefte in die gemeente te Jerusalem? Die diepste nood was dat die onderlinge gemeenskap, die geestelike band van die lidmate onderling gedreig het om te breek. Verbrokkeling van die gemeenskap van die heiliges het die jong gemeente in die gesig gestaar. Dan kan die gemeente as Liggaam van Christus nie groei, nie ontwikkel en uitbrei nie. Die verbrokkeling van die gemeenskap is veroorsaak deur nalatige versorging van ' $n$ bepaalde groep weduwees in die gemeente, nl. die weduwees van die Griekssprekendes. Dit bly 'n vraag of hierdie weduwees alleen op stoflike gebied verwaarloos is of dat daar ook 'n uitsluiting uit die gemeenskap van die heiliges was. Waarskynlik was stoflike verwaarlosing die gevolg van geestelike uitbanning uit die gemeenskap van die gemeente.

In elke geval is duidelik dat die betrokke weduwees gebrek 
gely het en stoflike versorging nodig gehad het. Wanneer ons aanneem dat dit saam gegaan het met 'n geestelike nood nl. dat hulle nie in die gemeenskap van die gemeente volledig opgeneem was nie, dan kan ons verstaan dat met die instelling van hierdie nog ongedifferensieerde amp aan albei die behoeftes van die weduwees tegemoet gekom kon word. Hiermee kom ons op die spoor van die wesenskenmerk van die amp van diaken. Die diaken is daar gestel om alles uit die pad te ruim wat die beoefening van die gemeenskap van die heiliges in die kerk belemmer.

Dieselfde kan natuurlik ook van die ouderling gesê word en daarom moet aan hierdie stelling nog iets toegevoeg word. Die diaken moet alle belemmeringe van maatskaplike en sosiale aard wat die beoefening van die gemeenskap van die heiliges bedreig, wegneem. Ons kan dit maar so breed as moontlik neem. Ons weet dat daar behalwe geestelike faktore soos twyfel, geloofskrisis, verslapping van die gebedslewe, verleiding deur die duiwel, wêreldsgesindheid ook maatskaplike, sosiale, psigiese, mediese faktore kan wees wat 'n mens verhinder om te kom tot volle diensbetoon in die gemeente van Christus.

Dit maak van die diaken natuurlik hoegenaamd nie 'n maatskaplike amptenaar, 'n sosiale werker, of 'n psigoterapeut nie, want die diakenamp is gerig op die opbou, die bloei en die uitbreiding van die Kerk as die Liggaam van Christus. Christus het hierdie amp ingestel om die Kerk werklik ten volle Kerk te laat wees.

L. Floor.

1 Handelinge van d:e agt-en-dertigste Sinodale Vergadering van die Gereformeerde Kerk in Suid-Afrika, p. 152.

2 A.w., p. 153.

3 P. Biesterveld e.a.: Het Diaconaat, 1907; G. Uhlhorn: Die Christeliche Liebestătigke.t, 1959; H. Krimm e.a: Das diakonische Amt der Kirche.

4 G. Voetius: Pol, Eccl., 1969, II cap. VIII, p. 502, 503.

5 H. Bouman: Het ambt der diakenen, 1907, p. 14.

6 P. Bieterveld: a.w, a.s., p. 223-225.

7 A. Kuyper: Encyclopaedie der Heilige Godgeleerdheid, 1894, III, p. 537, 538.

8 J. C. Rullmann: Diaconaal Handboek, 1929, p. 55 e.v.

$\theta$ K. Dijk: De dienst der Kerk, 1952, 232, 236.

10 S. U. Zuidema: Diaconaal Correspondentieblad, Nov. 1951.

11 F. H. von Meyenfeldt: De diaken als componist der gemeenschap, 1955, p. 22 e.v.

12 K. Dijk: a.w., p. 237.

13 O. C. Broek Roelofs: Bijbelse fundering van het diaconaat, in: Raad en Daad, no. 1.

14 J. van Klinken: Kerk en Gezinsmaatschaplijk werk, 1961, p. 104.

15 F. H. van Meyenfeldt: a.w., p. 33 e.v., 58.

16 H. N. Ridderbos: Wat is een diaken? in: Het Woord, het Rijk en onze verlegenheid, 1968, 9, 190.

17 O. C. Broek Roelofs: a.w., p. 6, 7. Aan die ander kant skrywe hy: „die e:genlijke taak van de diaconie blijft om de opbouw van de gemeenschap te dienen", p. 6 en verder: „Daarom kan de diaconale hulp ook omschre- 
ven worden als de hulp, die door geen ander wordt geboden", p. 7.

18 H. N. Ridderbos: a.w., p. 182.

19 H. Bouman: a.w., p. 12; J. Lonkhuyzen in: P. Biesterveld: a.w., p. 37; H. Hoekstra: Olie en wijn in de wonden, 1929, p. 79; J. Hoek, in: Diaconaal Handboek, 1929, p. 79.

20 J. Hoek: a.w., p. 84, 85.

21 H. Hoekstra: a.w., p. 33 en J. van Lonkhuyzen: a w., p. 40.

22 F. H. van Meyenfeldt: a.w., p. 36 e.v.

23 K. Dijk: De eenheid der ambten, 1949, p. 14, 15.

24 J. Hovius: Behoorden de diakenen tot den kerkeraad? 1951, p. 24.

25 G. Stăhlin: Die Apostelgeschichte, DNTD, 1985, 099.

26 G. Bornkamm: ThWB VI, p. 659.

27 E. Haenchen: Die Apostelgeschichte, 1968, p. 216, noot 1.

28 F. H. Grosheide: De Handelingen der apostelen I, 1942, p. 195.

29 F. H. Groshe:de: a.w., p. 195.

30 F. H. Grosheide: a w., p. 195.

31 L. Goppelt: ThWB VIII, p. 212, 213.

32 H. W. Beyer: ThWB II, p. 84.

33 A. M. Brouwer: De kerkorganisatic der eerste eeuwen $\in$ n wij, s.j., p. 32.

34 H. W. Beyer: a. art., p. 89.

35 H. W. Beyer: a. art., p. 90.

36 Calvyn: Komm. op Rom. 12 : 8; vgl. ook: Institusie IV, 3, 9.

37 H. N. Ridderbos: Aan de Romeinen, 1959, p. 280.

38 H. N. Ridderbos: Paulus, ontwerp van zijn theologie, 1966, p. 510. 